\title{
Factor Analysis of Risk Variables Affecting Occupational Injuries: A Field Study in Construction Projects
}

\section{Heidar Mohammadi, Ahmad Soltanzadeh,", Hamidreza Heidari², Abolfazl Mohammad- beygi $^{3}$, Mohsen Mahdinia ${ }^{2}$, Jamshid Rahimi ${ }^{4}$}

${ }^{1}$ Assistant Professor, Department of Occupational Safety and Health Engineering, Faculty of Health, Larestan University of Medical Sciences, Fars, Iran

${ }^{2}$ Assistant Professor, Department of Occupational Safety and Health Engineering, Faculty of Health, Research Center for Environmental Pollutants, Qom University of Medical Sciences, Qom, Iran

${ }^{3}$ Associated Professor, Department of Epidemiology and Biostatistics, Faculty of Health, Research Center for Environmental Pollutants, Qom University of Medical Sciences, Qom, Iran

${ }^{4}$ Assistant Professor, Department of Occupational Safety and Health Engineering, Faculty of Health, Alborz University of Medical Sciences, Karaj, Iran

* Corresponding Author: Ahmad Soltanzadeh, Department of Occupational Safety and Health Engineering, Faculty of Health, Research Center for Environmental Pollutants, Qom University of Medical Sciences, Qom, Iran. Email: soltanzadeh.ahmad@gmail.com

Received: $20 / 01 / 2019$

Accepted: 16/03/2019

How to Cite this Article: Mohammadi H, Soltanzadeh A, Heidari H, Mohammad-beygi A, Mahdinia M, Rahimi J. Factor Analysis of Risk Variables Affecting Occupational Injuries: A Field Study in Construction Projects. J Occup Hyg Eng. 2019; 5(4): 50-56. DOI: 10.29252/johe.5.4.50

\section{Abstract}

Background and Objective: Approximately, half of the occupational accidents are associated with the construction industry in Iran. Therefore, the factor analysis of risk variables affecting occupational injuries in the construction industry can lead to understanding and reducing the rate of injuries in these projects. The purpose of this study was to identify the risk factors affecting the types of injuries in construction projects based on factor analysis.

Materials and Methods: This field study was conducted on 65 active construction projects. The collected data included 55 injuries that were analyzed in SPSS software (Version 22.0) based on exploratory factor analysis and confirmatory factor analysis.

Results: The most frequent type of injuries regarding the order were spinal cord injury (41.2\%), cuts (32.4\%), organ failure (17.6\%), and multiple scars (8.8\%). Based on exploratory factor analysis, 26 indicator variables were classified in six groups of latent factors, including individual, occupational, unsafe conditions, unsafe acts, the type of injury incidence, and the type of injury. The findings of the confirmatory factor analysis of latent factors showed a significant correlation within these factors $(P<0.05)$. The goodness of fitness of the model was evaluated as good (RMSEA $=0.663$ ). Conclusion: The findings of the present study indicated that the incidence of injuries in construction projects can be due to the interaction between different factors and indicator variables. In addition, the results of factor analysis in this study indicated a difference between the effect of each of the indicator variables and latent factors.

Keywords: Construction Industry; Factor Analysis; Occupational Accident; Occupational Injury 


\section{تحليل عاملى ريسكفاكتورهاى اثرتذار بر آسيبهاى شغلى: يك مطالعه ميدانى در يروزههاى ساختمانى}

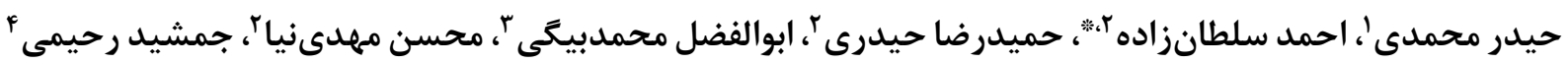

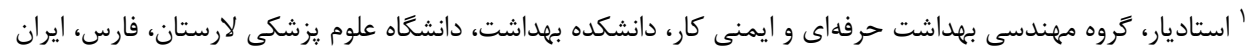

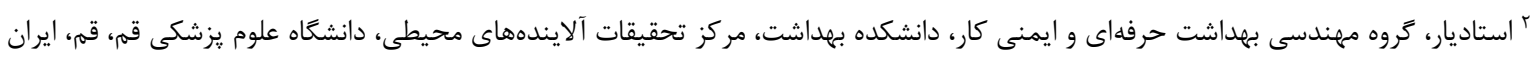

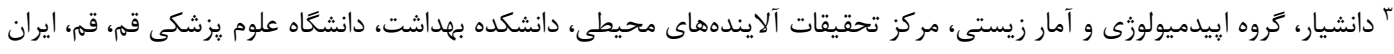

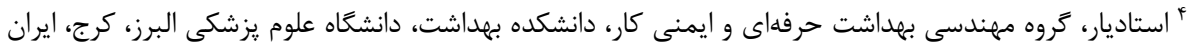

* نويسنده مسئول: احمد سلطانزاده، كروه مهندسى بهداشت حرفايى و ايمنى كار، دانشكده بهداشت، مركز تحقيقات آلايندهایى محيطى، دانشعاه علوم يزشكى قم، قم، ايران. ايميل: soltanzadeh.ahmad@gmail.com

جكيده

سابقه و هدف: نيمى از حوادث شغلى در ايران مربوط به ساخت و ساز مىباشد؛ بنابراين، تحليل عاملى

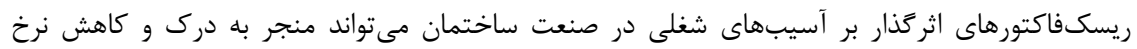

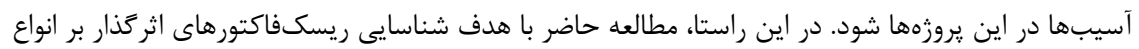

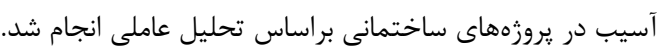

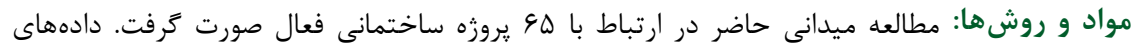

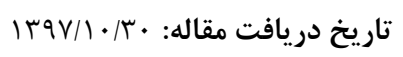
تاريخ يذيرش مقاله: تمامى حقوق نشر براى دانشكاه علوم يزشكى همدان محفوظ است.

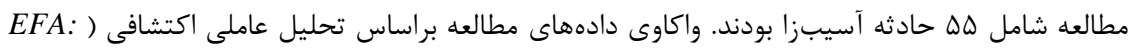
(CFAloratory Factor Analysis انجام شد. تحليل دادها نيز با استفاده از نرمافزار تحليلى

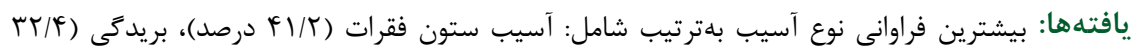

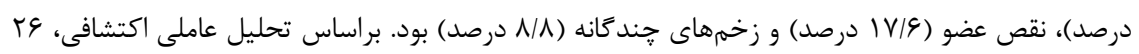

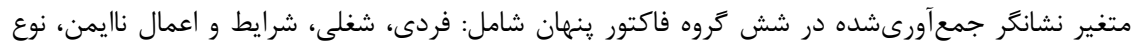

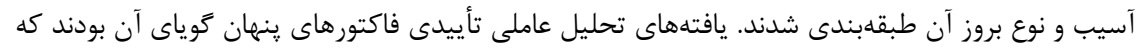

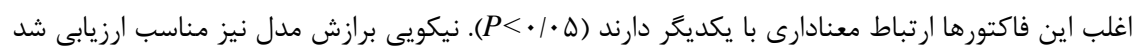

(RMSEA =•/.ศ $)$

نتيجهَّيرى: يافتههاى مطالعه حاضر بيانكر آن بودند كه بروز انواع آسيب در يروزهمهاى ساختمانى مىتواند

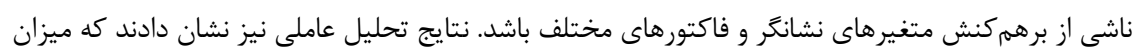

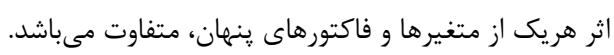

وازًٔان كليدى: آسيب شغلى؛ تحليل عاملى؛ حادثه شغلى؛ صنعت ساختمانى

نتايج برخى از مطالعات كوياى آن هستند كه · ب درصد از

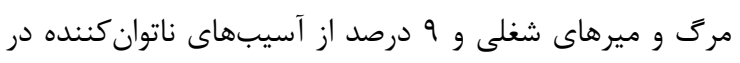

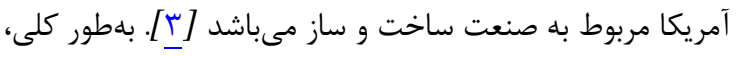

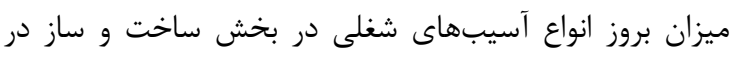

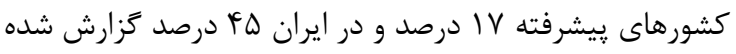

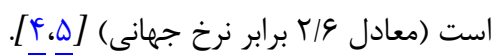

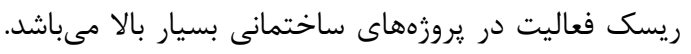

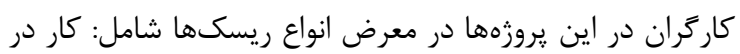

مقدمه براساس آمارهاى ارائهشده، حوادث حوزه ساخت و ساز بيش

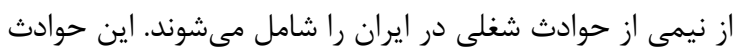

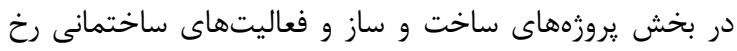

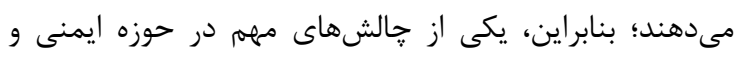

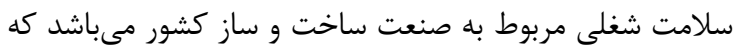

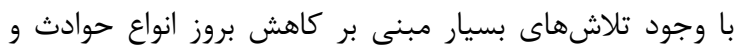

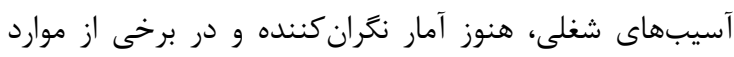
فاجعdبار مىباشند [1، 1.]. 
صورت كرفت. براى اين منظور، از نرمافزار مدليابى معادلات

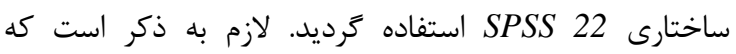

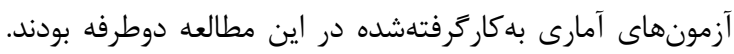

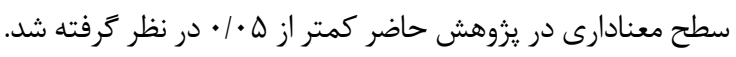

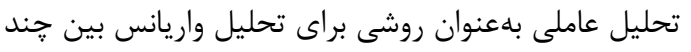
متغير وابسته براساس توصيف آنها بر حسب تعداي تهادي

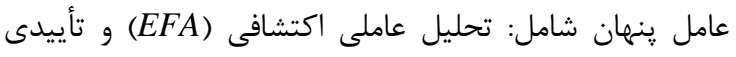
مى (CFA)

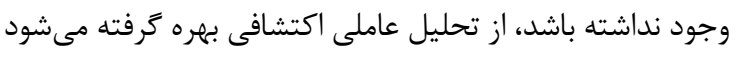

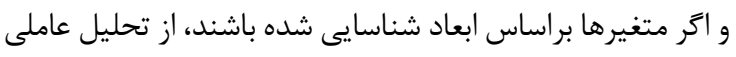

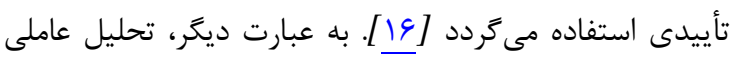

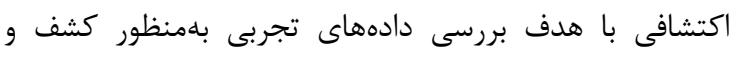

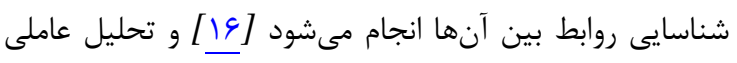
تأييدى مناسبترين شيوه براى سنجش روائ آنسيى (Vonstruct

(Validity

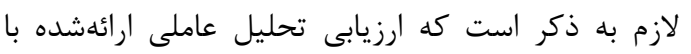

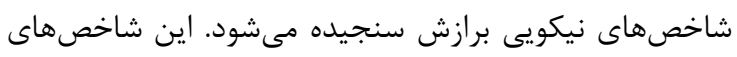

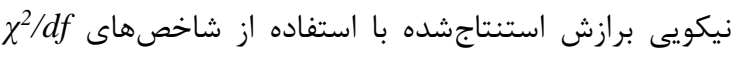
Root Mean Square Error of) RMSEA g ( $(\mathrm{r}-\mathrm{r})$ CFI Approximation

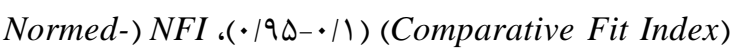
(Non-normed Fit Index) NNFI , (•/9 -••/1) (fit Index

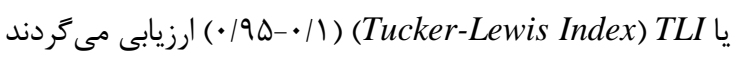

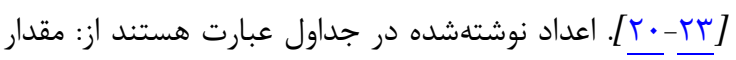

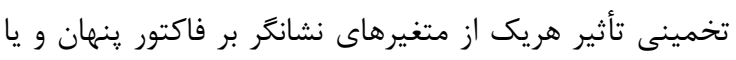

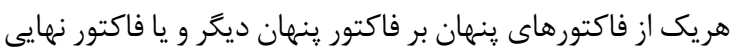
(كه در اين مطالعه انواع آسيب مى باشند).

\section{يافتهها}

نتايج توصيفى فاكتورها و متغيرهاى مورد مطالعه در جدول

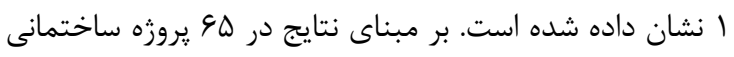

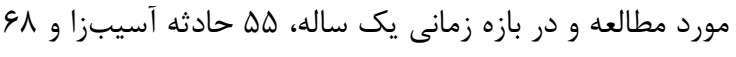

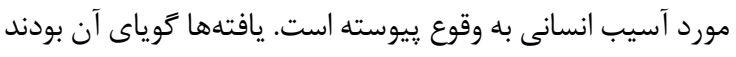

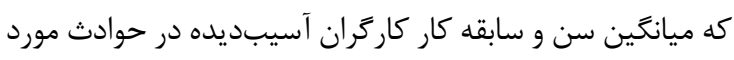

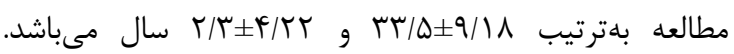

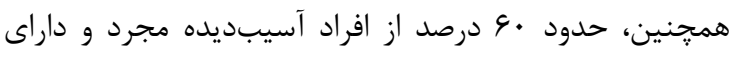

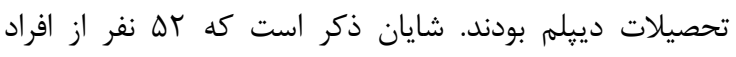

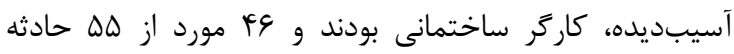

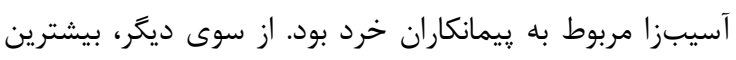

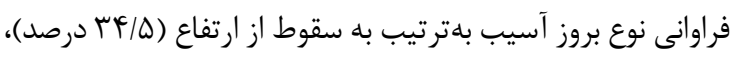

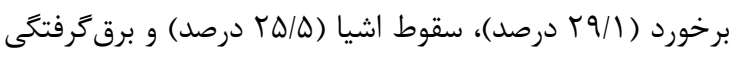

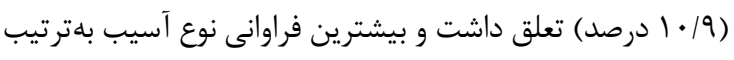

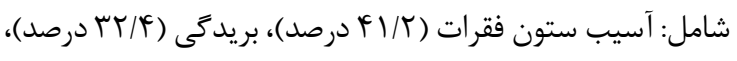

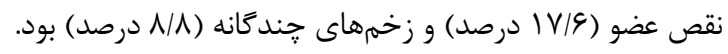

محيط باز، مواجهه با انواع ريسكفاكتورهاى محيطى و شرايط

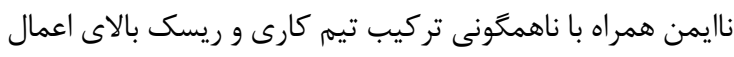

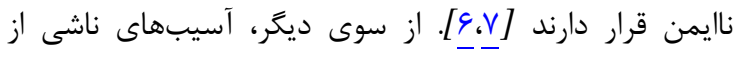

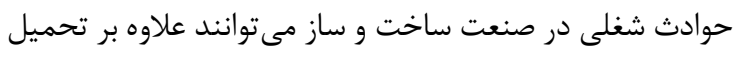

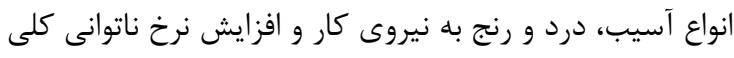

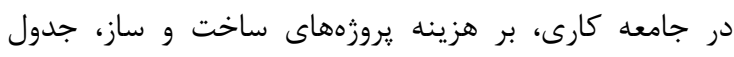

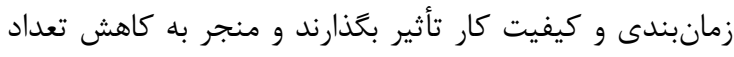

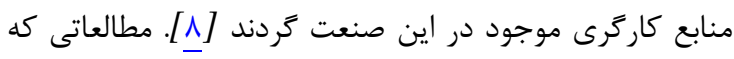

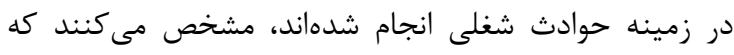

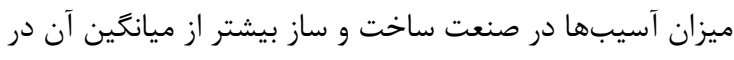

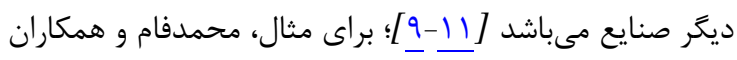

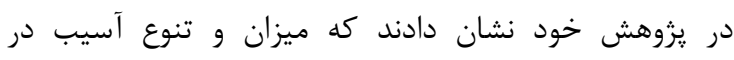

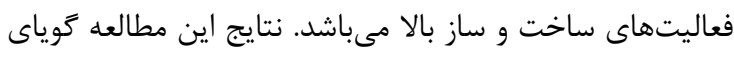

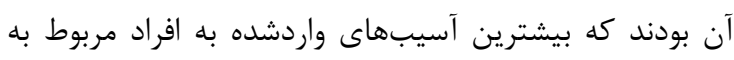

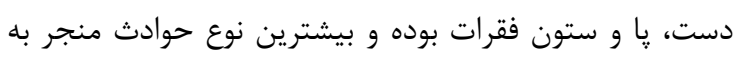

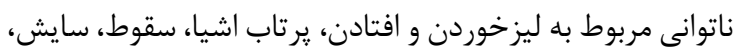

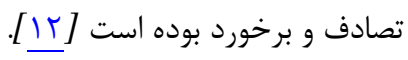

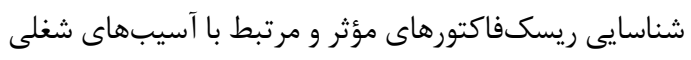

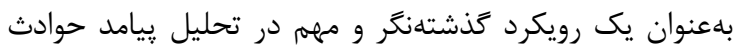

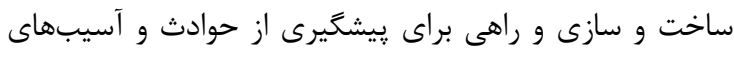

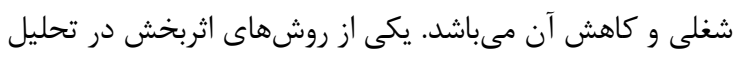

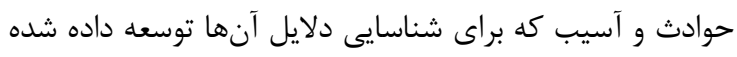

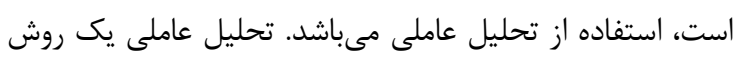

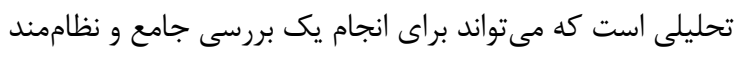

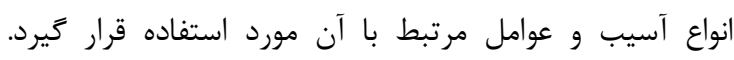

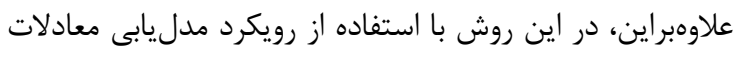

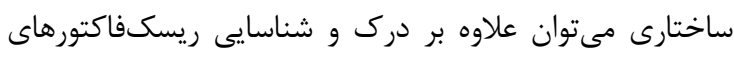

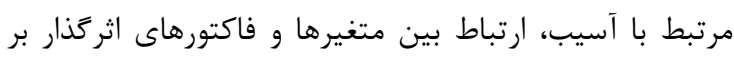

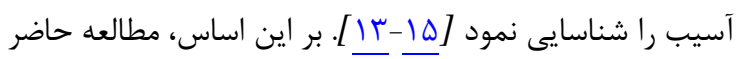

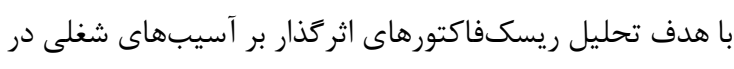

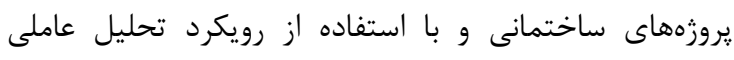

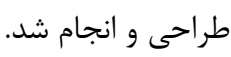

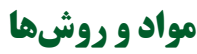

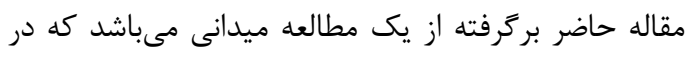

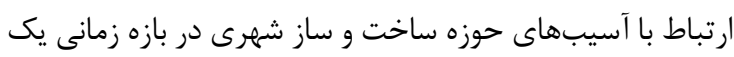

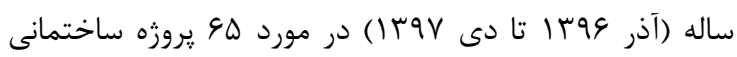

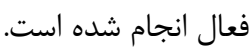

متغير اصلى مورد بررسى در اين بزوهش، انواع آسيبهاى

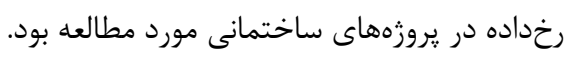

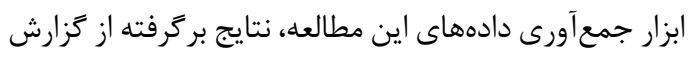

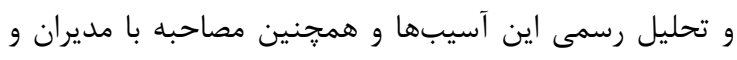

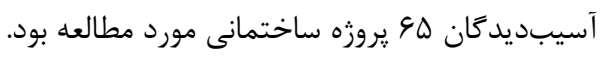

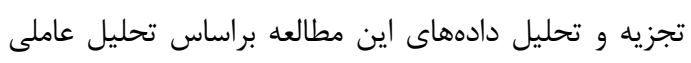


نتايج براساس צr متغير نشانگر جمعآورىشده در اين مطالعه و

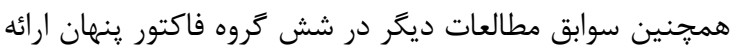

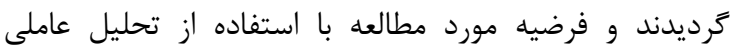

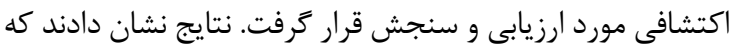
شش كروه فاكتورهاى فردى، شغلى، شرايط و اعمال نايمن، نوع

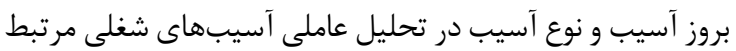

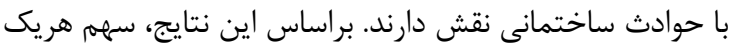

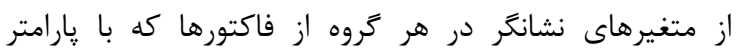

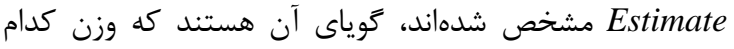
متغير تأثير حذارى بيشترى بر فاكتور دارد.

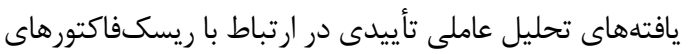

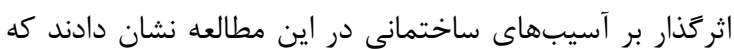

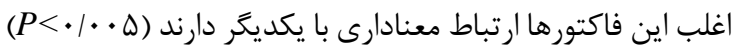

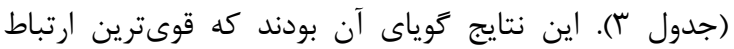

نتايج تحليل آسيبهاى رخداده در يزوهش حاضر نشان دادند كه علاوه بر متغيرهاى فردى و شغلى، برخى از متغيرهايى كه

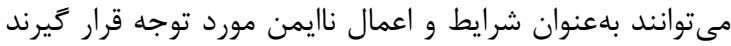

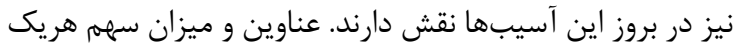

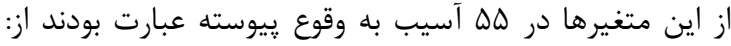

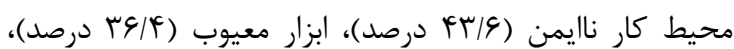

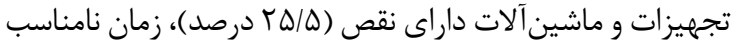

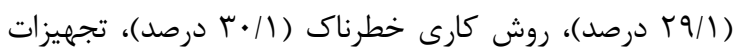

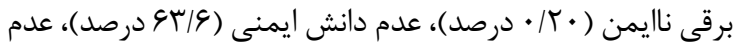

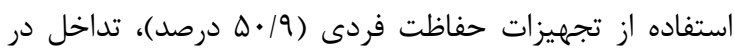

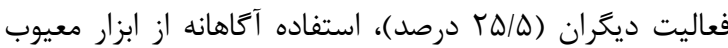

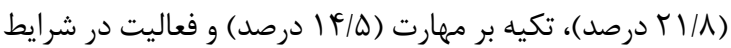

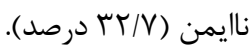
نتايج تحليل عاملى اكتشافى در جدول r ب ارائه شده است. اين

جدول ا: يافتههاى توصيفى مطالعه

\begin{tabular}{|c|c|c|}
\hline مقادير & & متغير \\
\hline$r r / q \pm \Delta / 1 \Lambda$ & & سن افراد آسيبد \\
\hline$T / \mathcal{F} \pm Y / T r$ & \multicolumn{2}{|c|}{ سابقه كار افراد آسيبديده (سال) } \\
\hline 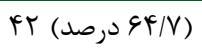 & مجرد & \multirow{2}{*}{ وضعيت تأهل } \\
\hline TF (T) & متأهل & \\
\hline 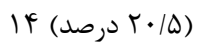 & كمتر از دييلهم & \multirow{3}{*}{ تحصيلات } \\
\hline$F \cdot\left({ }^{\prime}(\Delta, \Delta q / \cdot)\right.$ & دييلم & \\
\hline If & فوق دييلم & \\
\hline$\Delta r(ص)$ د & كارگر & \multirow{3}{*}{ 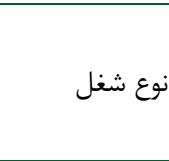 } \\
\hline F (ه/q) درصد & استادكار & \\
\hline $\mid r($ IV/\&) & فنى & \\
\hline $9(1,0 / 4)$ & ي ي & \multirow{2}{*}{ نوع يروره } \\
\hline F\& (4) & ي ي يمانكار خرد & \\
\hline 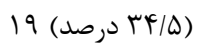 & سقوط از ارتفاع & \multirow{4}{*}{ نوع بروز آسيب } \\
\hline $19(9)$ (q/1) & 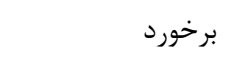 & \\
\hline If (Iر (ر & سقوط اشيا & \\
\hline $9(9)$ & برق كرفتگى & \\
\hline 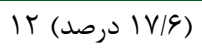 & نقص عضو & \multirow{4}{*}{ 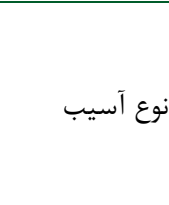 } \\
\hline$r \Lambda(\mu)$ ( & آسيب ستون فقرات & \\
\hline Tr (T) & بريدگى & \\
\hline $9(\Lambda / \Lambda)$ & زخمههاى جندكانه & \\
\hline
\end{tabular}

جدول r: نتايج تحليل عاملى اكتشافى

\begin{tabular}{|c|c|c|c|c|}
\hline سطح معنادارى & $S E$ & Estimate & متغير نشانگر & فاكتور ينهان \\
\hline- & - & $1 / \cdot$ & سن & \multirow{4}{*}{ 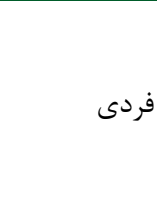 } \\
\hline$\cdot 1 \cdot \cdot 1$ & $\cdot / \cdot 1$ & $\cdot / V \&$ & سابقه كارى & \\
\hline$\cdot / \cdot r$ & $.1 .1 \mathrm{~V}$ & $\cdot \mid \Delta F$ & تأهل & \\
\hline$\cdot 1 \cdot \cdot 1$ & .1 .11 & س 1/1 & تحصيلات & \\
\hline$\cdot 1 \cdot \cdot 1$ & $\cdot 1 \cdot \Delta F$ & $1 / 14$ & ن نوع شغل & \multirow{2}{*}{ شغلى } \\
\hline- & - & $1 / \cdot$ & نوع يروزه & \\
\hline
\end{tabular}




\begin{tabular}{|c|c|c|c|c|}
\hline & & & & ادامه جدول r. \\
\hline$\cdot 1 \cdot \cdot 1$ & $\cdot / 1$ & $T / T r$ & محيط كار نايمن ل & \multirow{6}{*}{ شرايط نايمن } \\
\hline$\cdot 1 \cdot \cdot 1$ & $\cdot 1 \cdot 11$ & $1 / 14$ & 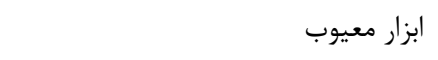 & \\
\hline- & - & $1 / \cdot$ & تجهيزات و ماشينآلات داراى نقص & \\
\hline$\cdot / \cdot r$ & $\cdot / 1 \mathrm{~F}$ & $\cdot / \Lambda$ & زمان نامناسب & \\
\hline$\cdot / \cdot \wedge$ & .1 .9 & $\cdot / \mathrm{r}$ & روش كارى خطرناى & \\
\hline$\cdot 1 \cdot \cdot 1$ & $.1 \cdot 19$ & $\cdot 190$ & تجهيزات برقى نايمن & \\
\hline$\cdot 1 \cdot \cdot 1$ & $\cdot / \cdot \wedge$ & $1 / \Delta T$ & عدم دانش ايمنى & \multirow{7}{*}{ اعمال نايمن } \\
\hline$\cdot 1 \cdot \cdot 1$ & $\cdot / r$ & $1 / \pi$ & عدم استفاده از PPE & \\
\hline$\cdot 1 \cdot \cdot 1$ & $\cdot / 11$ & $\cdot / \wedge 9$ & عدم استفاده از تجهيزات حفاظت فردى & \\
\hline$\cdot 1 \cdot \cdot 1$ & $\cdot / r \Lambda$ & $\cdot 191$ & تداخل در فعاليت ديكران & \\
\hline$\cdot 1 \cdot \cdot 1$ & $\cdot / \cdot 11$ & $\cdot / 4 q$ & استفاده آكاهانه از ابزار معيوب & \\
\hline$\cdot / \cdot v$ & $\cdot / r \Lambda$ & $\cdot / \mu F$ & تكيه بر مهارت & \\
\hline- & - & $1 / \cdot$ & فعاليت در شرايط نايمن & \\
\hline$\cdot / \cdot r$ & $\cdot / \cdot r$ & $r / T$ & سقوط از ارتفاع & \multirow{4}{*}{ نوع بروز آسيب } \\
\hline- & - & $1 / \cdot$ & برخورد & \\
\hline$\cdot \cdot \cdot r$ & $\cdot 1 \cdot 1$ & $\cdot / \mathrm{V} \Lambda$ & سقوط اشيا & \\
\hline$\cdot 1 \cdot \cdot 1$ &.$/ 14$ & $\cdot / \Delta F$ & برق كرفتگى & \\
\hline$\cdot 1 \cdot 1$ & $\cdot 1 \cdot 1$ & $\cdot \operatorname{lAr}$ & نقص عضو & \multirow{4}{*}{ نوع آسيب } \\
\hline$\cdot 1 \cdot \cdot 1$ & $\cdot / \cdot \wedge$ & I/FF & آسيب ستون فقرات & \\
\hline- & - & $1 / \cdot$ & 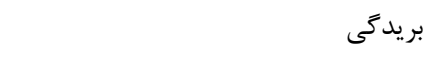 & \\
\hline$\cdot 1 \cdot \cdot \Lambda$ & $.1 \cdot 9$ & $\cdot / \mu F$ & زخمهاى جندكانه & \\
\hline
\end{tabular}

جدول با: نتايج تحليل عاملى تأييدى

\begin{tabular}{|c|c|c|c|}
\hline سطح معنادارى & $S E$ & Estimate & ارتباط دوطرفه بين فاكتورى \\
\hline$\cdot 1 \cdot \cdot 1$ & $\cdot 114$ & $1 / r T$ & فردى - شغلى \\
\hline$\cdot / \cdot \Delta$ & $\cdot 1 \cdot 1$ & $\cdot / 49$ & فردى- شرايط نايمن \\
\hline$\cdot 1 \cdot \cdot 1$ & $\cdot / \cdot r V$ & 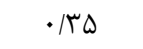 & فردى- اعمال نايمن \\
\hline$\cdot / \cdot r$ & 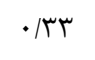 & $\cdot / \mathrm{VA}$ & فردى- نوع بروز آسيب \\
\hline$\cdot / \cdot r$ & $\cdot / \cdot r$ & $\cdot / \& \Delta$ & فردى-نوع آسيب \\
\hline$\cdot 1 \cdot \cdot 1$ & $\cdot / \cdot \Delta$ & $1 / 48$ & شغلى- شرايط نايمن \\
\hline $.1 \cdot \cdot 1$ & $\cdot / \cdot \Delta$ & $\cdot / \mathrm{VA}$ & شغلى- اعمال نايمن \\
\hline$\cdot 1 \cdot \cdot 1$ & $\cdot / \cdot r q$ & $1 / V$ & شغلى- نوع بروز آسيب \\
\hline$\cdot 1 \cdot \cdot 1$ & $\cdot 1 \cdot \omega$ & $\cdot \ln$ & شغلى- نوع آسيب \\
\hline$\cdot 1 \cdot \cdot 1$ & $\cdot / \cdot v r$ & $r / r q$ & شرايط نايمن- اعمال نايمن \\
\hline.$/ \cdot 11$ & $\cdot / 48$ & r/א & شرايط نايمن-نوع بروز آسيب \\
\hline$\cdot 1 \cdot \cdot 1$ & $\cdot / \cdot r$ & - /A & شرايط نايمن-نوع آسيب \\
\hline $.1 \cdot \cdot 1$ & $\cdot / \wedge$ & $r / \Delta T$ & اعمال نايمن- نوع بروز آسيب \\
\hline $.1 \cdot \cdot 1$ &.$/ \cdot 14$ & $1 / r$ & اعمال نايمن- نوع آسيب \\
\hline $.1 \cdot \cdot 1$ & $\cdot / \cdot 1$ & r/9. & نوع بروز آسيب-نوع آسيب \\
\hline
\end{tabular}

جدول fا: شاخصهاى نيكويى برازش مدل تحليل عاملى تأييدى

\begin{tabular}{|rr|}
\hline & \\
\hline$r / V T$ & $\chi^{2} / d f$ \\
.$/ .9 T$ & $R M S E A$ \\
.$/ 91$. & $C F I$ \\
.$/ 9 \vee \Lambda$ & $N N F I(T L I)$ \\
\hline
\end{tabular}

بلهترتيب مربوط به نوع بروز آسيب- نوع آسيب (• •و/؟)، شرايط

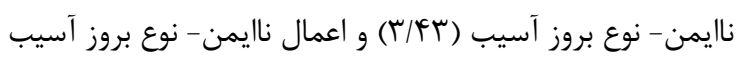

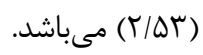

از سوى ديكر، نتايج مربوط به سنجش نيكويى برازش مدل

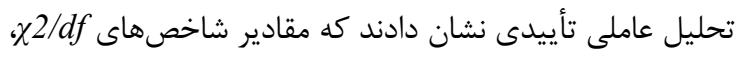
C RNFI (TLI) C RMSEA

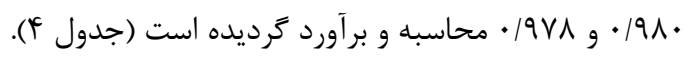


راستا، Arquillos و همكاران نشان دادند كه حوادث ساخت و

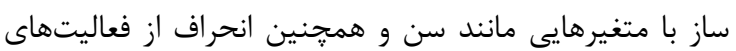

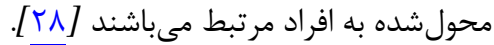
براساس نتايج تحليل عاملى ارائهشده در اين مطالعه مى تواند إندان كفت كه آسيبهاى شغلى در يروزههاى ساختمانى به دليل ماهيت فصلىبودن و نقش محدوديت زمانى در آنها بايد كانون بـاني توجه مسائل ايمنى، اهداف و برنامههاى كاهش حوادث و و آسيب

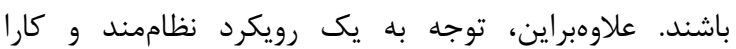

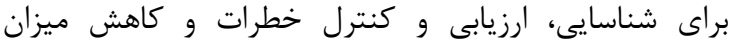

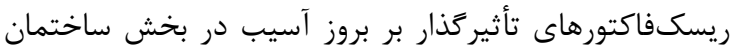

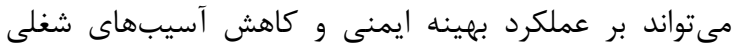
مربوط به آن اثر كذار باشد.

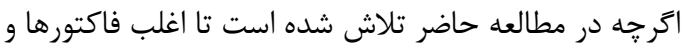

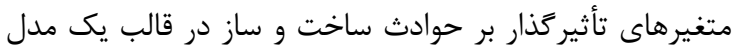

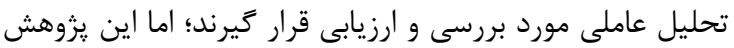

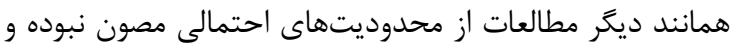

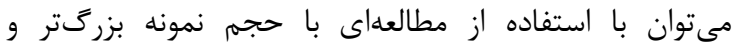

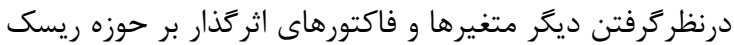

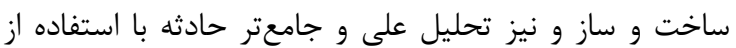
تكنيكهايى مانند تحليل دلايل ريشهاى به نتايج مطمئنتر و و

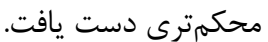

\section{نتيجه كيرى}

نتايج تحليل عاملى آسيبهاى شغلى در بخش ساختوساز

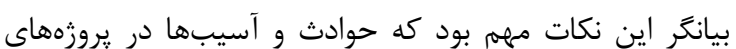
ساختمانى مىتواند تحت تاثير فاكتورها و متغيرهاى مختلف

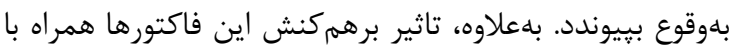

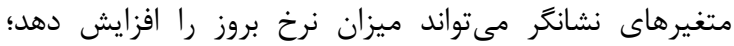

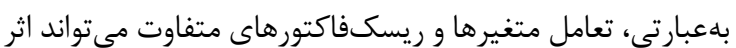
هممافزايى در ميزان وقوع اين آسيبها ايفا نمايد. بنابراين،

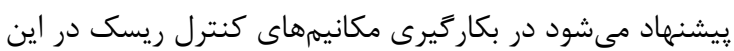
صنايع به اين يافته مهمم توجه بيشترى شود.

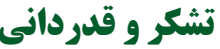

مطالعه حاضر بر مبناى طرح شماره 94NAV مصوب معاونت

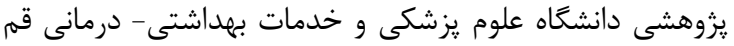

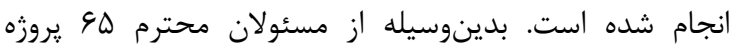
ساختمانى مورد مطالعه در اين يزوهش تشكر و قدردانى مى گرددد.

\section{REFERENCES}

1. Soltanzadeh A, Mohammadfam I, Akbarzadeh M. Studying disabling occupational accidents in the construction industry during two years. J Occup Hyg Eng. 2014;1(2):57-66. [Persian]
همان Fونه كه نتايج مطالعه حاضر نشان دادند، يافتههاى حاصل از بهكارگيرى مدل تحليل عاملى مى توانند تئورى جنه

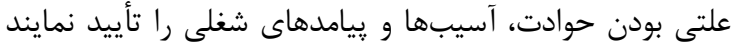

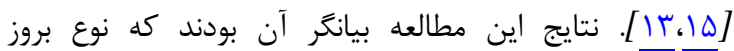

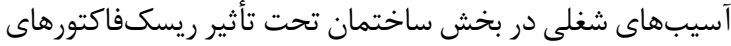

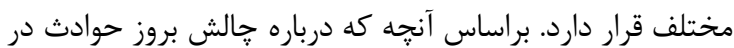

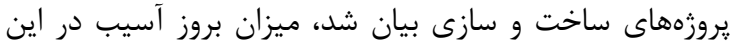

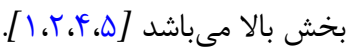
يافتههاى اين مطالعه كه در قالب مدل تحليل عاهل عاملى آسيبهاى شغلى در صنعت ساختمانسازى ارائه شدهاند، نشان دادند كه مجموعهاى از ريسكفاكتورها شامل: فاكتور فردى

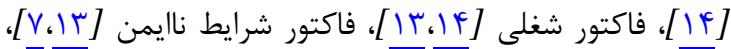

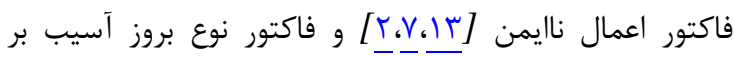

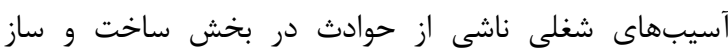
تأثير گذار مىباشند. در مطالعات مختلف، متغير سقوط از ارتفاع بهعنوان مهمترين

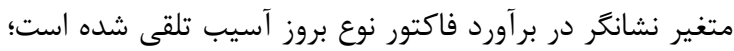

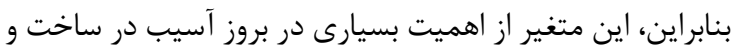

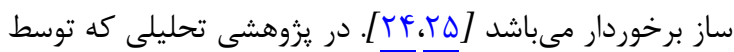
Grant

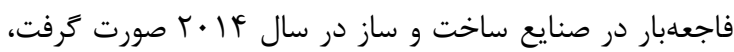

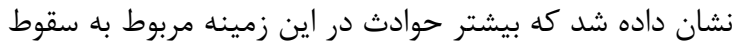

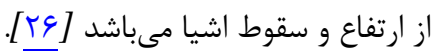

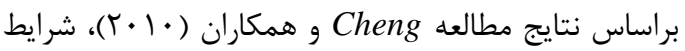

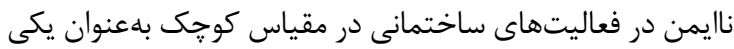

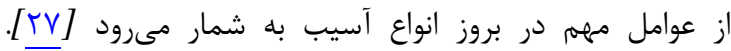

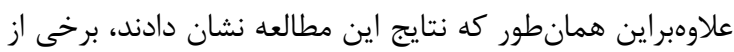
فاكتورها مانند فاكتورهاى فردى و شغلى شورئ بر اين ريسكفاكتور تأثير گذار مىباشند. نتايج برخى از مطالعات گوياى آن هستند كه فعاليت در يروزههاى ساختمانى شهرى به دليل عدم نظارت صحيح، عدم

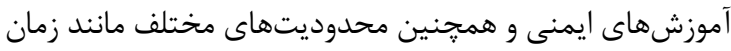
و هزينه يروزه مى تواند مستعد بروز انواع خطاى انسانى و اعمدين اعمال

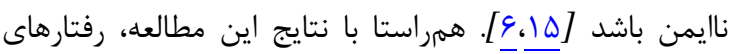

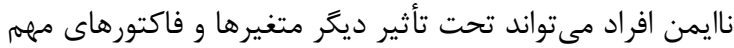
مانند فاكتور فردى، جو شغلى و شرايط نايمن قرار كيرد [ـإي].

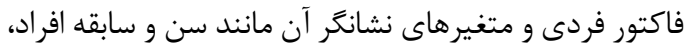

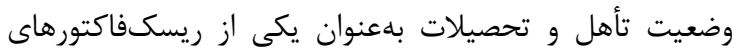

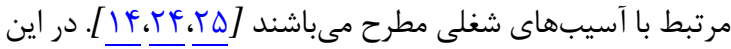

2. Soltanzadeh A, Mohammadfam I, Moghimbeygi A, Ghiasvand R. Exploring causal factors on the severity rate of occupational accidents in construction worksites. Int J Civil Eng. 2017;15(7):959-65. DOI: 10.1007/s40999-017-0184-9 
3. Abdelhamid TS, Everett JG. Identifying root causes of construction accidents. J Construct Eng Manag. 2000; 126(1):52-60.

4. Moradinazar M, Kurd N, Farhadi R, Amee V, Najafi F. Epidemiology of work-related injuries among construction workers of Ilam (Western Iran) during 2006-2009. Iran Red Crescent Med J. 2013;15(10):e8011. PMID: 24693372 DOI: 10.5812/ircmj.8011

5. Mohamadfam I, Soleimani E, Ghasemi F, Zamanparvar A. Comparison of management oversight and risk tree and tripod-beta in excavation accident analysis. Jundishapur $J$ Health Sci. 2015;7(1):e23554. DOI: 10.5812/ijhs.23554

6. Jafarnia E, Soltanzadeh A, Ghiyasi S. A combined health, safety and environment (HSE) risk assessment model based on PMBOK project management guide; a case study: development plan of the Islamic consultative assembly of Iran. J Occup Hyg Eng. 2018;4(4):47-58. DOI: 10.21859/johe.4.4.47

7. Soltanzadeh A, Mohammadfam I, Mahmoudi S, Savareh BA, Arani AM. Analysis and forecasting the severity of construction accidents using artificial neural network. Saf Promot Injury Prev. 2017;4(3):185-92. [Persian]

8. Pereira E, Taghaddos H, Hermann R, Han S, Abourizk S. A conceptual accident causation model based on the incident root causes. 5th International/11th Construction Specialty Conference, Columbia; 2015.

9. Dong X, Ringen K, Men Y, Fujimoto A. Medical costs and sources of payment for work-related injuries among Hispanic construction workers. J Occup Environ Med. 2007;49(12): 1367-75. PMID: 18231083 DOI: 10.1097/JOM.Ob013e $\underline{31815796 a 8}$

10. Silverstein B, Welp E, Nelson N, Kalat J. Claims incidence of work-related disorders of the upper extremities: Washington state, 1987 through 1995. Am J Public Health. 1998;88(12):1827-33. PMID: 9842381

11. Waehrer GM, Dong XS, Miller T, Haile E, Men Y. Costs of occupational injuries in construction in the United States. Accid Anal Prev. 2007;39(6):1258-66. PMID: 17920850 DOI: 10.1016/j.aap.2007.03.012

12. Ahmad $S$, Iraj M, Abbas $M$, Mahdi A. Analysis of occupational accidents induced human injuries: A case study in construction industries and sites. J Civil Eng Construct Technol. 2016;7(1):1-7.

13. Mohammadfam I, Soltanzadeh A, Moghimbeigi A, Akbarzadeh M. Confirmatory factor analysis of occupational injuries: presenting an analytical tool. Trauma Mon. 2017; 22(2):e33266. DOI: 10.5812/traumamon.33266

14. Mohammadfam I, Soltanzadeh A, Moghimbeigi A Akbarzadeh M. Modeling of individual and organizational factors affecting traumatic occupational injuries based on the structural equation modeling: a case study in large construction industries. Arch Trauma Res. 2016;5(3):e33595

PMID:

27800465

DOI: 10.5812/atr.33595

15. Mohammadfam I, Soltanzadeh A, Arsang-Jang S, Mohammadi H. structural equation modeling modeling (SEM) of occupational accidents size based on risk management factors; a field study in process industries. Health Scope. 2019;8(1):e62380. DOI: 10.5812/ihealthscope.62380

16. Thompson B. Exploratory and confirmatory factor analysis: Understanding concepts and applications. Appl Psychol Measurem. 2007;31(3):245-8. DOI: 10.1177/0146621606 $\underline{290168}$

17. Harrington D. Confirmatory factor analysis. Oxford: Oxford University Press; 2008.

18. Brown TA. Confirmatory factor analysis for applied research. New York: Guilford Publications; 2015.

19. Gatignon H. Confirmatory factor analysis. Statistical analysis of management data. New York: Springer; 2014. P. 77-154.

20. Hamdar SH, Mahmassani HS, Chen RB. Aggressiveness propensity index for driving behavior at signalized intersections. Accid Anal Prev. 2008;40(1):315-26. PMID: 18215564 DOI: 10.1016/j.aap.2007.06.013

21. Choi Y, Chung JH. Multilevel and multivariate structural equation models for activity participation and travel behavior. J Korean Soc Transport. 2003;21(4):145-54.

22. Chung JH, Lee D. Structural model of automobile demand in Korea. Transport Res Record. 2002;1807(1):87-91. DOI: 10.3141/1807-11

23. Golob TF. Structural equation modeling for travel behavior research. Transport Res Part B Methodol. 2003;37(1):1-25. DOI: 10.1016/S0191-2615(01)00046-7

24. $H u$ K, Rahmandad $H$, Smith-Jackson $T$, Winchester $W$ Factors influencing the risk of falls in the construction industry: a review of the evidence. Construct Manag Econ. 2011:29(4):397-416. DOI: 10.1080/01446193.2011.558104

25. Aneziris ON, Topali E, Papazoglou IA. Occupational risk of building construction. Reliabil Eng Syst Saf. 2012;105:3646. DOI: 10.1016/i.ress.2011.11.003

26. Grant A, Hinze J. Construction worker fatalities related to trusses: an analysis of the OSHA fatality and catastrophic incident database. Saf Sci. 2014;65:54-62. DOI: 10.1016/j. ssci.2013.12.016

27. Cheng CW, Leu SS, Lin CC, Fan C. Characteristic analysis of occupational accidents at small construction enterprises. Saf Sci. 2010;48(6):698-707. DOI: 10.1016/j.ssci.2010.02.001

28. López Arquillos A, Rubio Romero JC, Gibb A. Analysis of construction accidents in Spain, 2003-2008. J Safety Res. 2012;43(5-6):381-8. PMID: 23206511 DOI: 10.1016/j.jsr. 2012.07.005 